\title{
Zombie contracts, dark patterns of design, and 'documentisation'
}

\section{Kristin B. Cornelius}

Department of Information Studies, University of California, Los Angeles, United States of America, krisbcorn@g.ucla.edu

Published on 30 Jun 2019 | DOI: 10.14763/2019.2.1412

\begin{abstract}
Standard form consumer contracts (SFCCs) are drafted by businesses and presented to consumers on a non-negotiable basis, commonly appearing as Terms of Service (ToS) agreements in the margins of many popular web pages. This genre of contract is afforded its 'standard form' so as to increase the efficiency of transactions and save costs, which are ostensibly passed on to consumers. Since one party is generally less powerful in terms of access to information and resources, however, these contracts are often acknowledged as imbalanced and have been of concern for consumer rights in recent years. While some have characterized these issues as a 'duty to read' for consumers or as egregious terms and weak disclosures by drafters,' this project suggests at least part of the issues exist from a lack of consideration of the document itself (i.e., medium, format, authenticity, reliability, stability) and the processes that deem it 'standard.' It makes use of the disciplines that specialise in these topics, including document theory, library and information science, diplomatics, standards of records management, textual criticism and bibliography, and evidence to offer a revised perspective on SFCC issues and a new measure of assessment. Ultimately, it concludes that current governance is not adequate to address the issues of these agreements and suggests three principles, or shifts in concept: 1) standardisation, not standard practise; 2) explanation, not notification; and 3) documentation, not integration.
\end{abstract}

Keywords: Terms of Service (TOS), Standard form contracts, Records, Evidence, Governance

\section{Article information}

Received: 19 Mar 2019 Reviewed: 29 May 2019 Published: 30 Jun 2019

Licence: Creative Commons Attribution 3.0 Germany

Competing interests: The author has declared that no competing interests exist that have influenced the text.

URL:

http://policyreview.info/articles/analysis/zombie-contracts-dark-patterns-design-and-documentisation

Citation: Cornelius, K. B. (2019). Zombie contracts, dark patterns of design, and 'documentisation'. Internet Policy Review, 8(2). DOI: 10.14763/2019.2.1412

This paper is part of Transnational materialities, a special issue of Internet Policy Review guest-edited by José van Dijck and Bernhard Rieder.

Recently, a particular kind of spotlight has been placed on the popular social media company 
Facebook, and its CEO Mark Zuckerberg. Asking for more transparency in regard to behind-thescenes such as data collection schemes that lead to micro-targeted advertisements, this spotlight - which also targeted a few other technology conglomerates - was invoked by numerous leaks that revealed these activities. A New York Times report, for instance, published in March 2018 claimed that Facebook inadvertently provided academic Alexsandr Kogan (University of Cambridge) with access to the data of over 50 million user names (later changed to 87 million) and other personally identifying information through the use of a quiz application that Kogan created (Rosenberg et al., 2018). This information was then provided to the firm Cambridge Analytica (CA) whom had been hired by the Trump campaign team to profile users using this data for political influence through social media platforms. In the aftermath, including hearings with the U.S. Senate Judiciary and Commerce committees on April 10 and the U.S. House Energy and Commerce Committee on April 11 in which Zuckerberg testified, questions surrounding Facebook's knowledge of CA's data collection activities were at issue. After all, the collection went beyond the targeted users of Facebook (i.e., those who used the application that collected the data) to friends of those users and even to the data of non-users (Facebook, Social Media Privacy, and the Use and Abuse of Data, 2018). In particular, the company's Terms of Service (ToS) agreement was highlighted as it contained (at the time) some of the data collection policies for users of the platform. About two weeks after the hearings, Facebook itself was asked if it had read the ToS agreement laid out by CA in 2014 when it first allowed the firm to access its users' data, to which the company's chief technology officer Mike Schroepfer answered: "we did not read all of the terms and conditions" (Romm, 2018). For obvious reasons, this became a comedic headline in the days that followed.

Although this event brought ToS agreements to the forefront of public discourse, they were already in the purview of the issues related to the broader genre of contracts to which they belong - generically known as 'standard form contacts' or, more specifically for ToS, consumerfacing standard form contracts 1 . As the 'duty to read' by both parties can commonly be invoked as a defense associated with these types of contracts (Calamari, 1974), a familiar adage warns that we should read all of the fine print we sign or else the more powerful entity will most probably take advantage. Yet, this 'fine print' now exists within the corners and margins of nearly all of our online activities and often contains clauses that govern several important aspects of our lives, including copyright and ownership policies, dispute and jurisdiction information, acceptable use, even labour terms in many contexts (e.g., independent contractors, developers). Their parameters have wide-reaching implications for a giant-sized portion of the general public, yet we are desensitised to their presence to the point of almost total collective ignorance. One commonly cited study found that only about 1 or 2 in 1,0oo users access a ToS agreement for at least one second, producing an informed minority 2 of $0.2 \%$ that is "orders of magnitude smaller than the required informed minority size in realistic market settings and theoretical examples suggested in the literature" (Bakos et al., 2014, p. 2). Leib and Eigen (2017) presume that the cohort of users under the age of 35 years of age do not actually recognise this new form of contract as a contract at all 3 . At the very least, even though zombie contracts may appear as archetypal contracts on the surface, they have "several distinct features that sit in very deep tension" with traditional contract doctrine (p. 82). Anecdotally, over the last decade, it seems a common question asked when the topic is introduced is: "Are those actually contracts?"

Strategic, compliant, or even creative efforts to make users aware of their content, then, seem to have failed. In some sense, especially with the 'manufactured' consensus seen in recent legal discourse 4 , the quest to explore the means to transfer knowledge of these contracts to at least a portion of the population is nearly over. Sometimes, the logic follows: who would want to read so many thousands of words as a daily practice? It is not feasible nor rational to think 
consumers/users will do so, even if it is in their best interest (Ben-Shahar and Schneider, 2014). It has been claimed they care more about the features of their devices than the content of these agreements anyway ${ }_{5}$. One prominent author on the topic, Omri Ben-Shahar, cited a "grand bargain"-a term that was eventually disfavoured after a pushback by consumer advocacy groups 6-when he described how new legal descriptions of these contracts 7 embody a trade-off between a service and convenience of use:

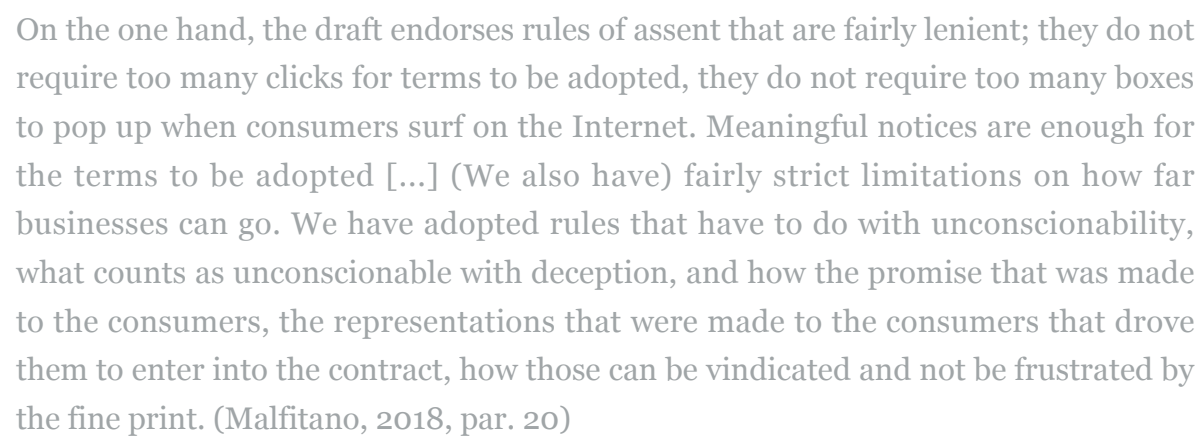

Ben-Shahar references forms and processes that have already been proven ineffective, including clickwrap agreements 8, and notification methods (i.e., mandatory disclosure, email, or banners), as desirable solutions even though he knows well their limits and failures -he literally co-authored the book on the topic (Ben-Shahar and Schneider, 2014). Yet recent legal proposals such as 'the grand bargain' allow for the documentation of this specific type of contract to be specially minimised in the name of convenience and usability for users, heavily favouring the drafting party and leaving users little choice or recourse. The more troubling aspect of BenShahar's statement is that he characterises the restraint of these features-"too many boxes to pop up" and "too many clicks"-as being for the consumer, which is only accurate if their true purpose (i.e., to notify users or gain their explicit consent) has been abandoned completely. At best, disclosure and consent efforts are read as routine or benign; at worst, their design choices signal to courts 'good faith effort' to notify users, while actually pressuring them toward unfavourable options (Forbruker Rådet, 2018). In fact, a recent study by the Norwegian Consumer Council (NCC) found multiple deceptive representations on the interfaces of Google, Windows 10 and Facebook in terms of privacy notices and choices. This study concluded that "dark patterns of design", including illusions of control and misleading wording that are meant to "nudge users toward privacy intrusive options" (p. 3), were numerous and rampant on these platforms.

Efforts to make known some of the egregiousness that can stem from SFCCs has been undertaken by consumer advocacy groups, including the Electronic Frontier Foundation (EFF) that wrote a series of white papers in 2013 on ToS agreements 9 and voluntary organisations such as TOSback.org that work toward archiving, tracking, and rating these contracts. A mainstream film called, Terms and Conditions May Apply (2013), documented how these contracts contributed to widespread, over-broad data collection activity three years before the Zuckerberg hearings. Most revelatory, a study undertaken in 2016 by a partnership between the Dynamic Coalition on Platform Responsibility (DCPR) and the United Nations' Internet Governance Forum found that ToS agreements affect human rights significantly in the areas of freedom of speech, privacy, and due process, particularly for marginalised and low-income communities (Venturini et al., 2016). Another study by Obar and Oeldorf-Hirsch (2018) found that most users do not read ToS and empirically concluded that the "vast majority [...] 
completely missed a variety of potentially dangerous and life-changing clauses" (p. 16). Moreover, Lieb and Eigen (2017) report how rather than to reinforce equity between classes, which was an early use of standard form contracting, differences in perception of the legal system in general motivates "elite customers" with more resources to only stop ToS egregiousness when it threatens them personally, and not for the fairness of the agreement in general or on behalf of less well-off consumers (p. 85).

Warnings about standard form contracts have appeared for at least over a century (Kessler, 1943; Leff, 1967; Gilmore, 1974). After the industrial period, ideals of standardised relations that ensured fair transactions as a way of subverting class systems were met with skepticism (Isaacs, 1917). Most recently, Leib and Eigen (2017) predicted "a zombie contract apocalypse" should these contracts continue to permeate every aspect of our digital lives without further regulation. The authors describe how:

zombie contracts [...] don the skin of contract, routinely get taken for contract, and at the same time, live by consuming contract's soul. Yet, it is exceedingly difficult to kill the undead, as any zombie scholarship will tell you. It is hard to kill zombies because they look so much like the real, living thing that has been killed to use as a host. (p.70)

The legal discourse and governance around SFCCs that supports and validates their use relies on certain myths about information presentation and user engagement that ultimately upset some of the traditional incentives to memorialise bargain terms. The desire to document the specifics of a bargain into a contract document generally relies on the fact that in cases of dispute, it is in the interest of both parties to ensure the terms are as clear as possible toward their own understanding. This is the case when two sophisticated parties are negotiating drafts of business-to-business contracts, which involves a process that includes agonising over each word, punctuation, and formatting change (Stark, 2007). However, with standard form contracts, including what Leib and Eigen call "zombie contracts", it is accepted that the majority of naïve parties do not read or understand the terms, and this responsibility is carelessly deflected onto the notion of an "informed minority" that will somewhere, somehow balance the asymmetry. In other words, even though much of the legal discourse recognises this asymmetry between the parties in the SFCC contracting situation, without an actual 'informed minority', the conundrum stands-all of the power to write, present, and validify these agreements stays with the drafter, with very little pushback from consumer-users, whom are generally uninformed and do not even realise they are engaging in a contract in the first place. More dangerously, the dynamics of the situation are now being confirmed rhetorically as notions of convenience, economics, and usability, which also favours the more powerful party (in terms of information and resources).

Leib and Eigen (2017) suggest that the best solution would be one that is created and monitored by academics, as they describe how this is the most trusted group for consumers. Specifically, they want to make use of technology to "leverage" academic expertise to "permit organisations to recast zombie contracts as live contracts" (p. 72, emphasis mine). Expanding on solutions from this vantage point, how might one regain some of the "liveliness" of previous or alternate contracting situations (e.g., paper contracts or B2B contracts)? So far, it seems their digital form has allowed them and their drafters more power-I believe we can use the very same source to even out the imbalance. This project suggests at least part of the issues exist from 1) a lack of consideration of the SFCC document itself (i.e., medium, format, authenticity, reliability, 
stability, boundaries, and ontology); and 2) the processes that deem it 'standard.' It begins by describing how actually standardising the document form of a SFCC by looking at studies of documents throughout at least a century of associated practices and criticism could be of use. I argue standardising would allow for a more granular understanding of this ubiquitous genre, providing the potential for future regulation that more discreetly articulates the areas of issue within the vast landscape of fine print that we now face.

In order to formulate a revised measure of assessment for the contract document, I make use of the disciplines that specialise in these topics, including document theory, library and information science, diplomatics, standards of records management, textual criticism and bibliography to offer a refreshed perspective on SFCC issues and develop implementable outcomes. Combined with an application of the phases of analysis offered by a documentengineering approach (Glushko and McGrath, 2008) that also utilises concepts and measures of assessment from these other disciplines, a much more comprehensive understanding of SFCCs might be had. This is especially important right now as, from a documentation and standardisation standpoint, I believe new digital forms of SFCCs are actually in their earliest wild, wild west stage and there is much to be done.

Initially, these specifications would serve several purposes, including more access for consumer advocacy groups, which could increase the "informed minority", as well as provide more document stability for the consumer should they be subject to the onus of burden of proof (Alliance for Justice et al., 2018). By targeting the form of the document and its documentation requirements (including its presentation, design, and methods of consent and notification), rather than the content of the contract itself, it avoids the 'freedom of contract' problem as drafters can continue to write the terms they wish. Thus, this document-engineered approach is a more elegant solution than those currently offered in that it would work toward making the contract more: a) Preservable/scrapable; b) Trackable/stable; c) Authentic/reliable (in a diplomatic sense); and d) Processable (machine-readable), while minimally infringing on the individual, democratic right to contract. Most importantly, however, SFCCs with these qualities, by facilitating an informed minority, could produce a counterbalance to any negative aspects from the asymmetries of knowledge and power. Even if recent empirical studies have claimed that the informed minority does not exist (Bakos et al., 2014), this project suggests that certain revised documentation, design, and explanatory requirements and practices could help fulfill its potential by giving motivated groups (e.g., consumer advocacy organisations) the ability to fully access and analyse these documents with the proper tools.

Ensuring that SFCCs have these qualities includes a multi-step approach that will take place over time. It might consist of the following:

1. Developing an ontology or type of document standard (i.e., metadata and markup) for SFCCs specifically, perhaps through an international standards body (such as the International Organization for Standardization [ISO]) or other technology organisation that considers the voices of multiple stakeholders. This standard could first be used to tag a data set (i.e., a corpus of current ToS) that would ultimately train a tool to automatically identify pieces of the contract. It could also be invoked in future regulation and compliance efforts.

2. Requiring a machine-readable format (json, csv, xml) that would allow for processing by consumer advocates and that allow for a controlled process of creation, classification, description and organisation;

3. Requiring a standard html version of the SFCC (without captcha) for scraping;

4. Requiring a PDF for user download (or automatic download onto keychain).

This list is not comprehensive; rather it is to show that a spectrum of relatively simple 
documentation and standardisation choices could enact a major change in the way SFCCs are presented and understood.

Ultimately, this study concludes that current governance is not adequate to address the issues of these agreements and suggests three principles, or shifts in concept around this genre of contract: 1) standardisation, not standard practice; 2) documentation, not integration; and 3) explanation, not notification. "Standardisation" in this sense relies on practices in regard to documents, information, and organisation that have been fine-tuned over time and has accessibility and knowledge for the general public in mind. This is a change in ambiguous notions of 'standard practice' that permeate contract discourse currently and are determined by the drafters and corporate entities, or those with the knowledge and resources to draft in their favour. Rather, the approach proposed by this project would make use of the expertise of a variety of stakeholders, including those who study user-consumers and documents, and would standardise so that those organisations that are serviced have the impetus to safeguard these contracts for consumers. This could also increase consumer trust both in these contracts particularly and service providers more generally.

"Documentation" in this sense refers to a systematic identification of the various components that make up the contract document, with practices such as description and bibliographical information noted and tracked with the various versions (e.g., with markup, metadata). This type of documentation also implicates a critical design approach to display and presentation. This is a turn from the 'integrated' (in a legal sense) contract documents that are afforded ideal textual status as a "fully [...] final and complete expression of all the terms agreed upon between (or among) the parties," which allows SFCCs to be in the form the drafter prefers (Rowley, 2011, p. 2). Instead the SFCC could be documented-a rematerialised image for the user-consumer through its understandability, accessibility, and presence as a text in the digital environment. This includes documenting changes and modifications in more practiced and developed implementations than obscure and ineffective notifications, the parameters and criteria for which are currently determined by drafters. It also includes a range of practices that could have benefits for consumers, including formatting the contract in a way that allows for processing and granular documentation, with markup that relays semantic information and has the potential for pinpointing areas that need further regulation. This latter use would benefit users perhaps indirectly through the knowledge gained by their processing by advocacy groups, but could have the greatest impact in terms of ensuring their fairness.

"Explanation" here refers to an actual engagement with reception and accessibility to knowledge for consumers based on alternate approaches, including counterfactual explanations that narratively explain a set of complex information through the relationship of two variables (Wachter et al., 2017), or decision provenance that shows a history of decisions made by artificial intelligence (AI) systems (Singh et al., 2018). These examples are a move away from the conventional sense of notification that has been proven to cause 'blindness' to its effect for the average consumer population. Explanatory mechanisms would be made possible through the documentation efforts of SFCCs that could prompt drafter compliance through regulation of certain problematic clauses. This would allow regulators to locate only those terms so problematic that most consumers would not agree in the first place (what the legal community calls "unexpected terms” 10 ), which are supposed to nullify a contract (“Restatement," 1981).

Changing the document form of SFCCs will not itself change the majority of users' reading practices; most, if not the vast majority of users, will still ignore them as they should. However, by paying attention to a contract as a document, we might be able to provide access to those 
interested in protecting consumer rights, including advocacy groups and researchers that seek to better understand their content and implications, and potentially fulfill the promise of an informed minority. Moreover, adapting some of these practices for the digital form of these contract documents using techniques such as metadata, markup, and classification built from information garnered from natural language processing (NLP) tools, could train machine learning (ML) tools for automatic tagging and potentially to eventually help correlate legal outcomes with language choices, which is an important interpretive step that is mostly missed by the average user. The automatic tagging of the pieces of the contract would contribute to describing the content of the contracts in a more rigorous fashion than simply requiring compliance to a schema on the part of the business, for instance. Most significantly, it might use the goals of access, literacy, and equity to process and standardise these digital documents in such a way as to provide a healthy counterbalance to current epistemologies of business (i.e., values of economics and convenience) preserved and perpetuated by the current contracting paradigm.

\section{STANDARD FORM CONSUMER CONTRACTS (SFCCS)}

SFCCs between consumers and businesses are 'standard form' so as to increase the efficiency of transactions and save costs, which are presumably passed on to the consumer (Kessler, 1943; Sales, 1953; Burke, 2000). These take the form of ToS agreements, End User License Agreements (EULAs), or more generally fine print, boilerplate, or adhesion contracts. Since one party, the consumer or user is commonly less powerful in terms of knowledge and resources, these contracts have been called out for being imbalanced in favour of the business entity ("the drafter") (Kessler, 1943; Patterson, 2010).

Much of the tension in the discourse around regulating SFCCs comes from a negotiation of the 'freedom of contract' principle that is seen as a cornerstone of a free market and democracy and underlies much of traditional contract doctrine. This freedom is often put in tension with enforcement mechanisms that regulate and dictate certain egregious aspects of the contract. Freedom of contract thus generally assures private ordering between individuals without intrusive top-down regulations (Micklitz, 2015).

The specific phrase "freedom of contract" might originate from Sir Henry Sumner Maine's wellknown passage from Chapter V of Ancient Law (1861) 11, in which he characterises the evolution from status (an ascribed position) to contract (a voluntary stipulation)]:
The movement of the progressive societies has been uniform in one respect. Through all its course it has been distinguished by the gradual dissolution of family dependency and the growth of individual obligation in its place. [...] But, whatever its pace, the change has not been subject to reaction or recoil, and apparent retardations will be found to have been occasioned through the absorption of archaic ideas and customs from some entirely foreign source. Nor is it difficult to see what is the tie between man and man which replaces by degrees those forms of reciprocity in rights and duties which have their origin in the Family. It is Contract. (par. 100)

Maine's description depicts the attitude towards contract during the $19^{\text {th }}$ century in which family and status obligations are replaced by individual ones and obligations with which one freely 
chooses to engage. In 1917, Nathan Isaacs produced one of the first detailed discussions of the adhesion doctrine 12 and argued against what he saw was an equating of 'contract' with 'agency' in an effort to counter the status-to-contract principle as a form of inevitable progress. He describes how the line from status to contract is not one that is simple, binaristic, or linear, as Maine suggests. Instead, he notes that what is actually being discussed is a progression from individualised relations to standardised relations, in which, throughout legal history, he states "has room not merely for one single line of progress in one direction or the other, but for a kind of pendulum movement back and forth between periods of standardisation and periods of individualization" ${ }_{13}$ (p. 47). At the time Isaacs was writing, standardisation in contracting was not viewed as a regulatory measure as it sometimes is today; instead, as is evident in Maine's description, it was seen as a further push toward more accessible and fair transacting for those with less power, where the freedoms and obligations of individuals are cemented as new ways of freely expressing their fundamental right to transact. In this way, standardisation at this time was seen as an extension of individual liberty by further promoting equality-an act of standardising relations for those with less power so that these relationships cannot inappropriately benefit one party over the other. Isaacs presents examples to the contrary, however:
that medieval hardening of relations known as feudalism was also, in its beginnings, a progress from contract to status. And those whose philosophy of history is a belief in the gradual development of liberty through the principle of contract have been forced to regard feudalism as a pause in human progress, an armistice in the war between two opposite ideas, status and contract-at best, a compromise, an exceptional, disturbing element in their whole scheme. Perhaps if we were able to go back to what we accept as standard family relations, we should find their basis, too, in the hardening of individual practices into rules. Perhaps even back of caste there was a progress from the individual non-standardised conduct to the standardised. (p. 40)

Current iterations of digital standard form contracts, then, compliment Isaacs' swinging pendulum model (and disruptions of the progressive model such as feudalism) as their 'standardisation' or allowance of 'standard form' seems to only benefit the powerful rather than those with less power, further solidifying these discrepancies.

Isaacs noticed early on how contractual relationships were "being displaced by uniform corporations organised under general laws" and how this negates any notion of equity as, in his words, "corporate powers are purely affairs of status" (p. 45). Particularly interesting for this paper, Isaacs describes how an "ignoring of forms is the triumph of the contract principle within the history of contracts," meaning that the freedom of contract principle has most importantly continuously obscured the form of the contract, which would attempt to provide some type of evidence for the intention of the parties (p. 47). In favour of seeking a kind of 'truth' of the bargain terms, freedom of contract allows "the meeting of free minds" supported by the "ideal of individual freedom in the negative sense of 'absence of restraint' or laissez faire" to determine truth (p. 47). In other terms, unchecked 'freedom of contract' can tend to facilitate ambiguous notions of truth rather than a move toward the standard practice of something concrete and based on documentary forms and practices. Legal scholar, Friedrich Kessler (1943) noted:

With the decline of the free enterprise system due to the innate trend of competitive 


\begin{abstract}
capitalism towards monopoly, the meaning of contract has changed radically. [...] Freedom of contract enables enterprisers to legislate by contract and, what is even more important, to legislate in a substantially authoritarian manner without using the appearance of authoritarian forms. Standard contracts in particular could thus become effective instruments in the hands of powerful industrial and commercial overlords enabling them to impose a new feudal order of their own making upon a vast host of vassals (p. 640).
\end{abstract}

As several authors predicted, standardised contracts have become increasingly affiliated with corporate entities and businesses and provided them a source of power to govern beyond the forums of their services alone. The forms these contracts take, the allowances they are given, and the types of authority they signal through their document form is one meaningful space where these issues need to be teased out in practice with an eye towards protecting consumers.

\title{
RHETORIC, PRESENTATION, AND DARK PATTERNS OF DESIGN
}

Lisa Gitelman (2014) notes how the word "document" descends from the Latin root docer, which means "to teach or show," suggesting that documents help "define and are mutually defined by the know-show function" (p. 1). In this way, documenting fulfills its purpose and is an "epistemic practice: the kind of knowing that is all wrapped up with showing, and showing wrapped with knowing" (p. 1-2). Gitelman notes how "closely related to the know-show function of documents is the work of no show, since sometimes documents are documents merely by dint of their potential to show: they are flagged and filed away for the future, just in case" (p. 2). Both "know-show" and "no-show" can rely on an "implied self-evidence that is intrinsically rhetorical", as "persuasion" is implicit in documentation practices (p. 2-3). By making this persuasion and the motivations of the practitioners that perpetuate it more explicit, it can fulfill the "horizon of accountability" that is a shared expectation of documentation practices. We might view documentation, in this way, as a site for the type of rhetoric that Plato suggests 14-without an analysis of his idealisation of truth. This provides an analytic framework within which practices of rhetoric may be assessed more broadly with documents and their various measures of standardisation, ontology, authenticity, reliability, and evidentiary qualities as the touchstone.

Standardisation, then, when viewed as both the process of producing information--either a type of information or information 'about' other information-- in a systematic manner could be seen through its documentation practice as an act of persuasion in the way Gitelman describes. While the power to name, classify, and standardise has been acknowledged as persuasive (Bowker and Star, 2000; Russell, 2014), its capacity to also work against acts of "no-show", where the document is hidden as a hyperlink or some other dislocated form, might also be seen as just as powerful. The disciplines rooted in library and information science, with the motivation to provide access to information to the public, might be a place to look for this effect.

Standardisation has been the science of many disciplines and its own study in the areas of library and information science since at least the late-nineteenth century, but as a general concept much longer (Rayward, 1994). Primarily concerned with the management (i.e., selection, collection, arrangement, indexing), retrieval, and dissemination of recorded 
knowledge, often with a pursuit of technical and systemic efficiency, documentation science studies the organisation of documents and the creation of standards and other mechanisms that aid this organisation. The European strand of the documentalists' movement (with Belgian lawyer Paul Otlet (1868-1944), and Henri La Fontaine) promoted the idea that for science to become a legitimate discipline, it needed a more efficient knowledge management system, especially in light of the proliferation of records with contemporary technological advances (Rayward, 1994). Otlet's Traité de Documentation published in 1934 was the culmination of a lifetime of thinking about problems of improving systems of organised knowledge and was an exploration of early documentation principles (describing what we now tend to call Information Storage and Retrieval). Initially, this study promoted a functional view of what could be considered a document; a term traditionally reserved for "text-like records" in the systemisation of knowledge organisation, but increasingly, the definition expanded the concept of document to include three-dimensional objects, including "sculpture, museum objects, and live animals" (Buckland, 1997, "Abstract”). By the 1920s, documentation was increasingly seen as a general term to incorporate the work of "bibliography, scholarly information services, records management, and archival work" (par. 5). At stake in these discussions are inquiries into what constitutes knowledge and documents and how these perceptions contribute to its accessibility, completeness, and participation in the transparency and accountability of an institution. If we are to accept that documentation is always necessarily an act of rhetoric in Gitelman's show/noshow characterisation, it might be considered that these studies could work in the direction of fulfilling Plato's task. In other words, using rhetoric towards the task of distinguishing, organising, and simplifying for the public the most 'truthful' information possible with their documentation practices (while perhaps still acknowledging that truth is hard to find).

Thus the disciplines that should be considered are those most practiced in this query and that are concerned with documents and their performance:

1. Diplomatics assesses the authenticity and reliability of an official document, and articulates the various channels and practices by which it gains legitimacy (e.g., Duranti, 1989, 1994);

2. Bibliography and textual criticism offer standards of editing and related documentation practices (e.g., Greg, 1950; Bowers, 1978; Tanselle, 1978; McGann, 1992);

3. Records management provides compliance requirements and measures of quality (e.g., International Organization for Standardization [ISO] 15489 standard for digital business documents);

4. Theories of evidence allows for practical and conceptual specifications in cases of dispute (e.g., Federal Rules of Evidence; Furner, 2004; Yeo, 2007; Anderson and Twining, 1991);

5 . Theories of documents and information help with documenting contracts appropriately by type, with the most useful and ethical classificatory and descriptive elements (e.g., Briet, 2006; Buckland, 1991; Day 2001, 2014).

At first glance, the familiarisation with certain design conventions or notions of standard practice for SFCC documents might not reveal the ways in which it is being de-documentised. The courts, for instance, might rely on design practices such as ALL CAPS for satisfactory disclosure, for instance, to signal good faith effort, even though we know it decreases the consumer's ability to read the text (Sullivan, 2012). Recent determinations about privacy policies, for instance, which are often treated as SFCCs (or 'transactional documents'), have been recently ordered by a trend of statutes, orders, and rules to be separated from other fine print agreements, including ToS. These efforts are meant to provide a solution to egregious data practices by making choices (and 'transactions') in regard to data collection more apparent for the consumer, as these policies often dictate the affordances of data collection. A 2011 "Consent Order" set out by the Federal Trade Commission (FTC), for instance, included a directive in 
which Facebook agreed it would not "misrepresent in any manner, expressly or by implication, the extent to which it maintains the privacy or security of covered information". The activities covered include the collection or disclosure of these activities, as well as the extent to which user data is accessible to third parties such as data brokers. Further, the specific directions on how it should be disclosed detail that the platform should:

\section{A. clearly and prominently disclose to the user, separate and apart from any "privacy policy," "data use policy," "statement of rights and responsibilities" page, or other similar document: (1) the categories of nonpublic user information that will be disclosed to such third parties, (2) the identity or specific categories of such third parties, and (3) that such sharing exceeds the restrictions imposed by the privacy setting(s) in effect for the user; and B. obtain the user's affirmative express consent. (Section II.A). (United States of America Federal Trade Commission, 2011)}

These restrictions refer to how the information in the ToS agreement is presented to users, documented in a way that seems fairer and more noticeable. Implicit in this presumption is the notion that returning to a document-form, rather than a piecemeal, dislocated fashion consisting of some of the information in various places (e.g., individual controls, FAQs, or as a clause or link within another agreement), might benefit users. If they are presented with a form they recognise, it is more likely they will understand they are engaging in a contract in the first place.

During the hearing on April 11 when Congressman Gene Green (Democrat-Texas) questioned Zuckerberg about the newly implemented GDPR laws that went into effect on 25 May 2018 in the EU, he described how they "require that the company's request for user consent be requested in a clear and concise way, using language that is understandable, and clearly distinguishable from other pieces of information including terms and conditions" (Facebook: Transparency and Use of Consumer Data, p. 52). Green is referring to the GDPR laws (specifically Article 2) as a result of the data policies of Facebook and similar companies. Zuckerberg answered this query with the deflection that they "are going to put [...] a tool that walks people through the settings and gives people the choices and asks them to make decisions on how they want their settings set [...] at the top of everyone's app when they sign in" (p. 53).

There are two issues with Zuckerberg's statement. First, Facebook's offer of more granular controls as alternatives to the legalese of ToS could work toward further confirming those ineffective consent 'tools' as signals of 'genuine effort' for courts (see Hillman, 2006). Second, this is especially dangerous for consumers as these alternate controls have actually been found to be associated with deceptive design practices, including "hidden privacy defaults" (p. 18-9), cumbersome or illusory privacy options (p. 31-4), and "positive and negative wording" that frames certain options as convenient ${ }_{15}$ (p. 22-5)--in other words, reward-punishment systems that are designed to favour and elicit consent for privacy-intrusiveness (Forbruker Rådet, 2018, p. 25-27). This study revealed the way the design of certain aspects of its presentation all contribute to what it is that is considered the contract document - the memorialisation of the transaction or bargain through documentation of the terms and consent to those terms. In its current form, the privacy policy is not projecting that it is a transaction or contract at all; instead, it looks like clauses, statements, notifications, FAQs, and individual 'controls'. If a privacy policy is considered to set out the transaction details of the deal a user makes with a service (i.e., an exchange of their data for the service) - a perception that is supported by its allowance as a SFCC that would stand up in court (and by its reliance on codes like UETA for 
consent, which are intended for sales of goods, not just services) - then its presentation should be forced to come off as a reliable and stable contract document. And if it is allowed that users do not read or understand most of these policies due to their standard form, then their form should actually be standardised by reliable practices and analysis.

\section{DOCUMENTATION AND STANDARDISATION SOLUTIONS}

This section presents a potential method and set of solutions for SFCCs, which makes use of a document-engineering framework that views the various components of a SFCC as a holistic document to which a user might be bound. Although other types of standardising and automating processes 16 have been suggested (Wilson et al., 2016; Sathyendra et al., 2017), this perspective is novel in that it suggests that the contract should be treated as a document, a record, and as a piece of evidence in the most standardised, rigorous sense. This would work against conventional practices of documentation that are developed by drafters and reaffirmed by courts, creating effectively a private conversation that leaves out users or advocates of users (Horton, 2009).

Document-engineering is an approach proposed by Robert J. Glushko and Tim McGrath outlined in their 2008 book that synthesises "complementary ideas from separate disciplines", including from information and systems analysis, electronic publishing, business process analysis and business informatics, and user-centered design (p. 27). The document-engineering approach uses both 'document analysis' that analyses text and 'task analysis' that analyses data and objects (pp. 29-30). It seeks to provide a spectrum of solutions addressing document and process specifications that, I argue, could lead to a better comprehension of SFCCs. This potentially includes a set of metadata, an XML schema or ontology that recognises various common components and assemblies of components of these documents, and a metamodel of a type of interpretation protocol for analysis.

Although it might be simply considered an early treatment on the construction of a relational database, Glushko and McGrath's unique angle considers the document type and form. For instance, they provide a description of the spectrum of document types to explain the ambiguity between them -they note how these lines are often blurry, but similar to a colour spectrum, we can recognise the difference between the colours red and blue (p. 10). The opposite ends of their spectrum are narrative documents and transactional documents, with the latter being involved in "document exchange" and thus more apt to benefit from a document-engineering approach. SFCCs are unique in a contractual sense in that there is no meaningful exchange, but rather they are presented 'narratively', so they exist somewhere in the middle and would also benefit from further distinction along this spectrum.

The authors propose the following phases of the document-engineering process (pp. 33-35):

1. Analysing the context of use: uses "business and task analysis techniques [to] establish the context of the document-engineering effort by identifying the requirements and rules that must be satisfied to provide an acceptable solution."

2. Analysing business process/apply patterns: "appl[ies] business process analysis to identify the requirements for the document exchange patterns needed to carry out the desired processes, collaborations, and transactions in the context of use"; identifies documents that are needed, 
but "only generally as the payload of the transactions."

3. Document analysis: "involves identifying a representative set of documents or information sources (including people) and analys[es] them to harvest all the meaningful information components and business rules"; identifies document needs beyond "payload" (see phase 2).

4. Component assembly: a "document component model" is developed that "represents structures and their associations and content that define the common rules for possible contexts of use."

5. Document assembly: uses the "document component model to create document assembly models for each type of document required"; move from analysing "tasks" to designing "new document models;" reuses "common or standard patterns to make the documents more general and robust."

6. Implementation: the conceptual models are encoded using "a suitable language to support their physical implementation."

The authors describe the 'document component model' as "a conceptual model that encompasses all the information components for any documents required by the context of use" (p. 354). This conceptual model looks like "specifications for interfaces, for generating code, or configuring an application that creates or exchanges new documents" created bottom-up and in a rigorous manner, then uses these models to "implement [...] solution[s] in an automated or semi-automated manner [...] to bridge the gap between knowing what to do and actually doing it" (p. 354). Put simply, the documents in question are first analysed contextually and then individually to identify their various components, and then patterns across these components are recognised and assembled into a document hierarchy that describes a single instance of a set of components for a type of document.

1. Analysing the context of use: For SFCCs, this phase will outline what the ideal solution would accomplish-the information ideally communicated or explained, processed, extracted, understood, and preserved, based on the SFCC situation. This might look like identifying the clauses that need supplemental information, the information needed for evidentiary reasons, or the specifications for the automatic identification of clause types. The questions being asked in this first phase is: What would be the ideal document outcome needed to encourage a voice for consumers? What is the most important information to communicate? What are the best ways to communicate this information?

It will consider the discourse, governance, and issues outlined in this governance around SFCCs, as well as ontological and epistemological conversations about what it means to be a document or record in an information system or on a digital interface. This includes recognising the need to retain the right to freedom of contract, as well as acknowledging that certain social and political paradigms might solidify power imbalances amongst the parties of this type of contract, which warrants sacrifices this freedom to some extent.

2. Analysing business process/apply patterns: This phase is the one most dissimilar from the original document-engineered process. Rather than looking at 'business processes', this phase looks slightly tangentially at how legal processes and associated discourse specify the "ultimate payload document". The question being answered in this phase is: What is necessary for drafters to comply with basic SFCC requirements? How is this type of presentation afforded by legal discourse and what is it lacking? How have document standards been used previously to 
regulate other types of contracts?

This phase will be informed by theories of contract, records, and documents, but also by using foresight to suggest how SFCCs might be regulated once in a document-engineered form. These predictions might be gained by an analysis of similar situations that have standardised contract and other regulations that have had success regulating by document form. The most important outcome of this phase will be to decipher between the types of compliance efforts that would be required of businesses (e.g., format or schema requirements) and the work that would be done by other entities such as consumer advocacy groups. These two efforts most probably would be iterative and inform each other, but a clear distinction is necessary to set out the types of regulation that might be needed.

3. Document analysis: For SFCCs, this phase considers a selection of contracts to analyse with various document analysis tools by researchers and consumer advocacy groups. While this also might include any member of the public who wishes to analyse these documents, the most likely interested parties would be consumer advocacy groups with a vested interest in understanding these contracts. The tools used to analyse SFCCs might include text analysis tools that include topic modeling or clustering to show language data (e.g., word frequency, word proximity, common topics). The information garnered from these analyses shows some of the patterns that occur amongst these documents, which is important to build the necessary schematics from the bottom-up (rather than imposing a schema onto the genre in a top-down fashion). Moreover, this process should be iteratively revised (along with phases 4-6) in order to continually reflect how these contracts are written and implemented in practice. This preserves the ability for drafters to exert their right of freedom to contract to some extent and keeps the standard reflective of actual practice. Such a method might include the NEH-funded text mining and analysis tool Lexos 17 built by computer scientists from Wheaton College, Massachusetts and medieval scholar Dr. Scott Kleinman (Cal. State University, Northridge), that is described as being designed with a workflow that helps a researcher to be "mindful of the many decisions made in [their] experimental methods" (par. 1).

4. Component assembly: As document component models strive to define all the necessary components to maximise and minimise redundancy for each individual document, this phase will strive to identify the components of the SFCC document from the analysis that took place in phase 3 . These components might include structural components, content components, and associative components (p. 34). Different types of documents or, in this case, contracts, might make use of the same pattern of components, and these patterns should be identified and reused. For instance, related SFCCs (e.g., privacy policies, copyright policies) might have some of the same components, including "Data Use", "Tracking", "Jurisdiction", "Legal Notice", or others.

This process, since it is an act of 'naming' and thus exerting some type of bibliographic control onto the document and those affected by it, should be cognisant of the critical lens applied to information science work. This includes recognising that while organising is essentially "bringing all the same information together", that information is often standardised habitually, which risks sacrificing complexity in the name of simplicity and economy, a common issue in the creation of information organisation systems (Svenonius, 2009, p. 80). Additionally, the naming practices can either become habitual or seemingly benign and can mask the politics, strategy, and implications behind the labeling decisions (Bowker and Star, 2000). These are relevant concerns for SFCCs, although it might be argued that they are already being classified according to the wishes of the drafters, and the goal of this project is to use information 
organisation to work against these current manifestations.

5. Document assembly: Once the document components are identified, this phase would consider the relationships between the components to figure out the best possible configuration of individual contract documents. This ideal schema would strive to "define on documentspecific view of the more complex document component model" (p. 463). In Glushko and McGrath's conception, the "document component model [the outcome of phase 4] [is] the roadmap of a city that depicts the entire network of roads. A particular document assembly model [the outcome of phase 5] describes a specific route through that network" (p. 464).

This phase is informed by the literature on information studies, that argues that semantics and naming are always not exact (Svenonius, 2009). However, as the document-engineering approach strives to produce document exchanges that "require unambiguous clarity in semantic interpretation", this project also strives to reduce ambiguity as much as possible, even if the documents are not being 'exchanged' in the same sense (p. 463). It would also make use of previous work done in this regard, including the list of Topics and Cases identified by TOS;DR, the results of the language processing tools, and previous XML schemas such as the one created by the nonprofit OASIS in 200718.

6. Implementation: First, a corpus of current and past SFCCs would be analysed to find topics, relationships, establish definitions, and build a standard (metadata, markup, and ontology). Then, a corpus of ToS documents (such as that provided by TOSBack.org) would be marked up with this new standard by a group of experts on these contracts and then used to train a machine learning tool to be able to automatically tag a document. ToS agreements organised in this fashion would make a difference in terms of the information extracted for consumer advocacy groups, policymakers, and consumers. Lastly, a holistic analysis should be conducted of the usefulness of the possible regulatory activity that could stem from this documentengineered SFCC (i.e., what a tag would implicate compliance-wise). One particularly important study of this phase, which would be a result of the analysis from the other phases, would be a study of the reliability and authenticity of a SFCC from the concerns of diplomatics (Duranti, $1989,1994)$. Questions of this nature would be: does the contract perform according to an understanding of a conventional contract form (is it a 'reliable' contract)? Does this inform consumers of the nature of its creation or changes (is it an 'authentic' contract)? These queries would aid the outcome of the description process toward labelling according to communication, literacy, and access, rather than just for simplification, ease of use, or efficiency.

\section{CONCLUSIONS AND PRINCIPLES}

Ultimately, this project suggests three principles, which are each a shift in concept around an issue with SFCCs and the way they are discussed in legal contract discourse. Along the way, I offer potential methods (e.g., document-engineering) and identify potentially novel solutions (e.g., new types of explanation) that would aid in these shifts. Additionally, the solution offered in this paper suggests that the contract should be treated as a document, a record, and as a piece of evidence in the most standardised, rigorous sense, not simply as a step in registration processes or as a series of displaced privacy controls. However, the shifts in the concepts themselves are most important and they could be achieved by various means, not all of which are listed here. 


\section{STANDARDISATION, NOT STANDARD PRACTICE}

Legal discourse around SFCCs allows for presumptions of knowledge based on 'standard practice' and 'unexpected terms', meaning there is no preemptive mechanism in place to standardise the information in the contract-it is left up to the drafters to decide what to put into the contract and how to present the information. Notions of "value judgments" that determine what is meant by 'standard practice', or the determination of "oppressive clauses", however, rely on presumed trajectories of the effects of the clauses and literacy of consumerusers in terms of how well drafters can predict these trajectories when forming the agreement (Murray, 1982; Garamello, 2015). A recent trend in paring economic and legal theory has prompted some SFCC scholars to argue that since it is accepted and not rational for consumers to read the terms, predicting bias or reasoning on the part of the consumer might produce even more ambiguous results that weigh down the autonomy of the contracting process (Ayers and Schwartz, 2014).

Although this line of thinking is often an exercise in the freedom of contract principle, other legal scholars have noted that it prompts a trend of "rampant drafting isomorphism" wherein the drafters copy and paste any seemingly relevant clause from other similar agreements 19. Thus, it does not seem the case that "efficiency is a focal point at the drafting stage, and, therefore, unlikely that resulting from contracts can be described as efficiency maximizing machines." In this view, everything is included in these contracts as an "exercise in risk aversion" and as a way to "keep them at the same cost level as their competitors" (p. 83). In other words, the "race to the bottom" has already occurred, so no future cost-savings can be expected to benefit the consumer (p. 83).

Creating document assemblies from a process of document-engineering, for instance, would help standardise the SFCC document as it would provide a controlled process of creation, help identify the genre and type of contract, and allow for the complimentary nuanced and holistic assessments of these contracts. Common components and assemblies should be identified by professionals who are experts on SFCCs. An example from another genre of contracts is the American Institute of Architects' (AIA) Contract Document System that provides type and version numbers for a wide variety of contract documents put together by 35 industry professionals from various fields, such as construction, design, insurance, and law 2o. Other models include those from certain industries that already have their own organisations for standardising contracts, such as the Insurance Service Organization that is well regarded in the legal insurance world, which also registers their contracts numerically 21 and provides economic statistic information that verifies the usefulness of these contracts.

\section{DOCUMENTATION, NOT INTEGRATION}

US laws that came out of the Uniform Commercial Code (U.C.C.) such as the Uniform Electronic Transaction Act (UETA) and the E-Sign laws that were intended to streamline the process of digital transactions and to harmonise some of the discrepancies of transacting across state borders, however, might have subverted this debate and exacerbated the issues in some of the arguments for the unconscionability of SFCCs. By allowing commercial interests not to have to keep paper copies of their electronic documents as evidence of transactions, the UETA effectively gave legally binding status to electronic documents and signatures without requiring a paper component (Section 7 (c)). The E-Sign laws broadened the notions of agreement and awareness even further by claiming "the mere fact of use, or of behavior consistent with acceptance" is "sufficient to evidence that party's willingness." Regardless of the explicitness of the consent mechanism, other aspects of SFCCs can supersede any of the understanding of the contract egregious unilateral modification clauses, make the other promises in the contract 
"completely illusory, as this term essentially asserts that the online service provider will only be bound to the terms in the ToS for as long as the online service provider decides not to change those terms" (Preston and McCann, 2012, p. 23). In other words, for the user, the concept of the document as a stable entity that could be potentially understood is disrupted by the mere fact that the service provider could change the document at any time without their knowledge of this change. As Preston and McCann (2012) ask: "If the service provider can change the contract at will, why bother to call it a contract at all?” (p. 25)

The concept of unilateral modification in the context of SFCCs allows for the continual modification of terms. As it stands right now in the US and with new confirmations of contract doctrine such as the Draft, unilateral modification clauses and practices are mostly allowed; some jurisdictions require notification of changes, but very little other documentation is required (Horton, 2009). Compared with other legal systems such as the EU's, where this type of editing is forbidden entirely, a lack of attention to the continual 'instability' of these texts seems problematic; moreover, markers of the appearance of stability creates the illusion that the texts are either stable or immaterial (nonexistent), and thus these contracts and their drafters can have free rein to include any terms at will without an acknowledgement of the change, or else with the assurance that readers will ignore any notification efforts. Once this instability is recognised, however, certain bibliographic practices if implemented carefully, such as archiving, editing, and documenting using metadata schematics, might be offered in producing a more useful record for an adherent unfamiliar with its content.

Both the terms used to articulate the concept of a stable text and the terms used to critically revise that concept as perpetually unstable might similarly provide a lens to describe the state of SFCCs. Descriptions of textual edits such as those described by the Greg-Bowers-Tanselle method, could also be adapted to articulating certain egregious displays of authority on the part of drafters and continual modifications, rather than romanticise (or ignore) authorial intention, could be viewed as dangerously persistent from the validity afforded by court opinion. Ultimately, viewing modifications as 'edits' in the textual sense broadens the notion of modification and allows for a more nuanced engagement with any changes to SFCCs. Rather than invisible behind-the-scenes changes with dull or annoying notification practices, it might be imagined that textual and bibliographic theories could offer a new vocabulary that could revise the understanding of this process for adherents, including delineating between vertical and horizontal revisions 22, for instance, and/or making determinations of 'ideal texts' (Greg, 1950) that would make markers of authoritative or intentional power more explicit.

\section{EXPLANATION, NOT NOTIFICATION}

One thread in zombie contract scholarship (Grether et al., 1986; Ayers and Schwartz, 2014) claims that instead of regulating for this 'market-imperfection' (i.e., asymmetric knowledge ${ }_{23}$ ), evidence-based disclosure methods would be more helpful. In fact, mandatory disclosure remedies, including those that specify how disclosure should occur (e.g., the UETA's 'posting rule') or how it should be written (e.g., notions of transparency, simplification, plain language rule), are currently the primary method used to remedy these agreements. For instance, the 'posting rule' specifies the timing and method of disclosures 24. Some (Hillman, 2006) have responded to these claims by noting how disclosures might exacerbate the issues they try to solve by seeming to satisfy notification requirements when, actually, they have the opposite effect for adherents and rather add to the issue of "information overload". Other scholars (Marotta-Wurgler, 2011; Bakos et al., 2014; Ben-Shahar and Schneider, 2014) are on the more extreme end of the spectrum than the 'disclosureites' and have responded with studies that they believe have proven "entirely" that disclosure methods do not work. These studies rely on 
evidence that they argue proves users would not engage or try to understand the information even if made transparent by simple and clear presentation.

This shift in concept would work toward the goal of explanation, rather than conventions of notification, because it would move beyond the banners or emails to which consumers have become accustomed and strive to find points of the contract that need further information to understand. The fulfillment of this principle might upset ill-conceived notions of consumer engagement as it could be possible to consider that understanding the contract-seeing it as a 'material' object with consequences-could be a beneficial goal of contracts, perhaps especially for SFCCs. In practice, this might mean that "meaningful disclosure", for instance, works toward disrupting familiar forms such as the annoying cookie notification, and assent means understanding the contract within the context of other information. Drucker (2013) claims that "more attention to acts of producing and less emphasis on product" help promote "the creation of an interface that is meant to expose and support the activity of interpretations, rather than to display finished forms," which might be "the antidote to the familiarity that blinds us" (par. 42).

Ultimately, I argue the tenets of contract doctrine that have been refined and studied over many centuries should not be abandoned in favour of new types of contracts, yet the new forms of contracting and their relationship to notions of actual practices of standardisation and documentation. Moringiello and Reynolds (2014) claim that traditional contract law is sufficient to handle new forms of contracting such as digital SFCCs. In one sense, it may seem naïve or even neglectful to assume that contract doctrine must not change in order to accommodate new iterations of zombie contracts that have proven detrimental effects for consumers. In another sense, however, if the law changes in such a way that they are accommodated, such as what was proposed in the draft of the Restatement of Consumer Contracts this year, some of the issues with SFCCs might be codified further and exacerbated in the future.

In 1978, legal scholar Ronald C. Griffin wrote: "We are faced with an historic choice in contracts. We can lump together standard forms and classic contracts, or we can treat the former differently" (p. 20). In the decades since, it seems standardised contracts have been "lumped together", not only with other types of contracts, but also with new technological forms of these documents. Contract law changed very little from the First Restatement of Contracts in 1932 to the early 2000s, due to no "disruptive" technological developments in this field during these years (Moringiello and Reynolds, 2014). Even at that early stage in the late 1970s, Griffin understood "the rules of the quiet past are simply too cumbersome to deal with the complexities of a stormy contract future" (p. 21). We have now reached that future, and it is indeed stormy and full of zombies. In order to prevent continual deflections (and apologies) of some of these issues by CEOs such as Zuckerberg at his hearings, a more nuanced and rigorous understanding of SFCCs should be undertaken by a variety of stakeholders. In other words, the argument of this paper boils down to the simple statement that standard form contracts, especially those that are consumer-facing, should actually be standardised, which requires that they be viewed as documents and held to the specific measures of assessment and practices associated with that form. Only then might we be able to change the rhetoric and presentation of these contracts to fulfill the show function (in Plato's view) and work toward an actual transparency of the workings of current technical service platforms. 


\section{REFERENCES}

Advocates for Basic Legal Equality, Inc., Allied Progress, Americans for Financial Reform, Americans for Financial Reform, Arkansans Against Abusive Payday Lending Arkansas Community Institute, Berkeley Law Consumer Advocacy \& Protection Society, ... Woodstock Institute. (2018, October 12). Reject Council Draft No. 5 of the Restatement of Consumer Contracts (Sept. 19, 2018). Retrieved from National Consumer Law Center website: https://www.nclc.org/images/pdf/udap/letter-reject-council-draft-no.5-oct2018.pdf

Alliance for Justice, Allied Progress, Arkansans Against Abusive Payday Lending, Berkeley Law Consumer Advocacy \& Protection Society, Center for Responsible Lending, Consumer Action, ... Woodstock Institute. (2018, January 10). Re: Council Draft No. 4 of the Restatement of Consumer Contracts. Retrieved from National Consumer Law Center website: https://www.nclc.org/images/pdf/udap/26-ali-comments-council-draft-4.pdf

Anderson, T., \& Twining, W. L.. (1991). Analysis of Evidence: How to Do Things with Facts Based on Wigmore's Science of Judicial Proof. Evanston, IL: Northwestern University Press.

Ayres, I. \& Schwartz, A. (2014). The No-Reading Problem in Consumer Contract Law. Stanford Law Review, 66, 545-610. Retrieved from

https://www.stanfordlawreview.org/print/article/the-no-reading-problem-in-consumer-contra ct-law/

Bakos, Y., Marotta-Wurgler, F., \& Trossen, D. R. (2014). Does Anyone Read the Fine Print? Consumer Attention to Standard Form Contracts [Working Paper No. 195]. New York: New York University.

Ben-Shahar, O., \& Schneider, C. (2014). More Than You Wanted to Know: The Failure of Mandated Disclosure. Princeton: Princeton University Press.

Bowers, F. (1978). Greg's 'Rationale of Copy-Text' Revisited. Studies in Bibliography, 31, 90161. Retrieved from https://www.jstor.org/stable/40371676

Bowker, G., \& Star, L. (2000). Sorting Things Out: Classification and its Consequences. Cambridge, MA: The MIT Press.

Briet, S. (2006). What is Documentation? English Translation of the Classic French Text (R. E. Day, L. Martinet \& H. G. B. Angehelescu, Eds. \& Trans.). Lanham, MD: The Scarecrow Press, Inc.

Buckland, M. K. (1991). Information as thing. Journal of the American Society of Information Science, 42(5), 351-360. doi:10.1002/(SICI)1097-4571(199106)42:5<351::AID-ASI5>3.0.CO;23 Available at http://people.ischool.berkeley.edu/ buckland/thing.html

Buckland, M. K. (1997). What is a Document? Journal of the American Society of Information Science, 48(9), 804-809. doi:10.1002/(SICI)1097-4571(199709)48:9<804::AID-

ASI5>3.o.CO;2-V Available at http://people.ischool.berkeley.edu/ buckland/whatdoc.html

Burke, J. J. A. (2000). Contract as Commodity: A Nonfiction Approach. Seton Hall Legislative Journal, 24, 285-317.

Calamari, J. D. (1974). Duty to Read: A Changing Concept. Fordham Law Review, 43(3), 
341-362. Retrieved from http://ir.lawnet.fordham.edu/flr/vol43/iss3/1

D'Agostino, E. (2015). Contracts of Adhesion Between Law and Economics: Rethinking the Unconscionability Doctrine. Cham: Springer. doi:10.1007/978-3-319-13114-6

Day, R. E. (2001). The Modern Invention of Information: Discourse, History, and Power. Carbondale, IL; Edwardsville, IL: Southern Illinois University Press.

Day, R. E. (2014). Indexing it All: The Subject in the Age of Documentation, Information, and Data. Cambridge, MA: The MIT Press

Drucker, J. (2013). Performative Materiality and Theoretical Approaches to Interface. Digital Humanities Quarterly, 7(1). Retrieved from

http://www.digitalhumanities.org/dhq/vol/7/1/ooo143/ooo143.html

Duranti, L. (1989). Diplomatics: New Uses for an Old Science. Archivaria, 28, 7-27. Retrieved from https://archivaria.ca/archivar/index.php/archivaria/article/view/11567

Duranti, L. (1994). Reliability and Authenticity: The Concepts and their Implications.

Archivaria, 39, 5-10. Retrieved from

https://archivaria.ca/archivar/index.php/archivaria/article/view/12063

Facebook, Social Media Privacy, and the Use and Abuse of Data: Hearing before the Committee on the Judiciary and the Committee on Commerce, Science and Transportation, United States Senate, 116th Cong. (2018, April 10). (Testimony of Mark Zuckerberg). Retrieved from https://www.judiciary.senate.gov/download/o4-10-18-zuckerberg-testimony

Facebook: Transparency and Use of Consumer Data. Hearing before the Committee on Energy and Commerce, United States House of Representatives, 116th Cong (2018, April 11). Retrieved from https://docs.house.gov/meetings/IF/IFoo/20180411/108090/HHRG-115-IFooTranscript-20180411.pdf

Forbruker Rådet. (2018). Deceived by Design: How tech companies use dark patterns to discourage us from exercising our rights to privacy [Report]. Oslo: Forbruker Rådet. Retrieved from https://fil.forbrukerradet.no/wp-content/uploads/2018/o6/2018-06-27-deceived-bydesign-final.pdf

Furner, J. (2004). Conceptual Analysis: A Method for Understanding Information as Evidence and Evidence as Information. Archival Science, 4(3-4), 233-265. doi:10.1007/s10502-0052594-8

Gilmore, G. (1974). The Death of Contract. Columbus, OH: Ohio State University Press.

Glushko, R. J. \& McGrath, T. (2008). Document Engineering: Analyzing andDesigning Documents for Business Informatics and Web Services. Cambridge, MA: The MIT Press.

Griffin, R. C. (1978). Standard Form Contracts. North Carolina Central Law Journal, 9(2), 158-177. Retrieved from https://archives.law.nccu.edu/ncclr/vol9/iss2/3

Gitelman, L. (2014). Paper Knowledge: Toward a Media History of Documents. Durham, NC: Duke University Press.

Greg, W. W. (1950). The Rationale of Copy-Text. Studies in Bibliography, 3, 19-36. 
https://www.jstor.org/stable/40381874

Hillman, R. (2006). Online Boilerplate: Would Mandatory Website Disclosure of E-Standard Terms Backfire? Michigan Law Review, 104(5), 837-856. Retrieved from https://repository.law.umich.edu/mlr/vol104/iss5/2

Horton, D. (2009). The Shadow Terms: Contract Procedure and Unilateral Amendments. UCLA Law Review, 57, 605-667. Retrieved from https://www.uclalawreview.org/the-shadow-termscontract-procedure-and-unilateral-amendments/

Isaacs, N. (1917). The Standardizing of Contracts. Yale Law Journal, 27(1), 34-48. Retrieved from https://digitalcommons.law.yale.edu/ylj/vol27/iss1/6/

Kessler, F. (1943). Contracts of Adhesion-Some Thoughts about Freedom of Contract. Columbia Law Review, 43(5), 629-642. doi:10.2307/1117230 Available at https://digitalcommons.law.yale.edu/fss_papers/2731

Klass, G. (2019). Empiricism and Privacy Policies in the Restatement Consumer Contract Law. Yale Journal on Regulation, 36(1), 45-115. Retrieved from https://digitalcommons.law.yale.edu/yjreg/vol36/iss1/2/

Korobkin, R. (2003). Bounded Rationality, Standard Form Contracts, and Unconscionability. University of Chicago Law Review, 70(4), 1203-1295. Retrieved from https://www.jstor.org/stable/1600574

Leff, A. A. (1967). Unconscionability and the Code-The Emperor's New Clause. University of Pennsylvania Law Review, 115(4). https://doi.org/10.2307/3310882

Leib, E. J., \& Eigen, Z. J. (2017). Consumer Form Contracting in the Age of Mechanical Reproduction: The Unread and the Undead. University of Illinois Law Review, 65-108. https://ir.lawnet.fordham.edu/faculty_scholarship/883/

Levitin, A.J., Kim, N. S., Kunz, C. L., Linzer, P., \& McCoy, P. A. (2019). The Faulty Foundation of the Draft Restatement of Consumer Contracts. Yale Journal on Regulation 36(1), 447-470. Retrieved from https://digitalcommons.law.yale.edu/yjreg/vol36/iss1/7/

Malfitano, N. (2018, June 25). Criticism Follows Powerful Law Group to Next Project - A ‘Troubling' Take on Consumer Contracts. Forbes. Retrieved from https://www.forbes.com/sites/legalnewsline/2018/o6/25/criticism-follows-powerful-law-grou p-to-next-project-a-troubling-take-on-consumer-contracts/

Marotta-Wurgler, F. (2011). Will Increased Disclosure Help? Evaluating the Recommendations of the ALI's "Principles of the Law of Software Contracts". University of Chicago Law Review, 78(1). Retrieved from

http://lawreview.uchicago.edu/publication/will-increased-disclosure-help-evaluating-recomme ndations-ali\%E2\%80\%99s-\%E2\%80\%9Cprinciples-law-software

McGann, J. J. (1992). A Critique of Modern Textual Criticism. Charlottesville: University Press of Virginia.

Micklitz, H. W. (2015). The Transformation of Enforcement in European Private Law:

Preliminary Considerations. European Review of Private Law, 23(4), 491-524. 
Moringiello, J. M., \& Reynolds, W. L. (2014). The New Territorialism in the Not-So-New Frontier of Cyberspace. Cornell Law Review, 99(6), 1415-1440. Available at http://scholarship.law.cornell.edu/clr/vol99/iss6/5

Murray J. E., Jr. (1982). Standardized Agreement Phenomena in the Restatement (Second) of Contracts. Cornell Law Review, 67(4), 735-784. Retrieved from http://scholarship.law.cornell.edu/clr/vol67/iss4/6

Obar, J. A., \& Oeldorf-Hirsch, A. (2018). The biggest lie on the Internet: ignoring the privacy policies and terms of service policies of social networking services. Information, Communication \& Society. doi:10.1080/1369118X.2018.1486870

Patterson, M. R. (2010). Standardization of Standard-Form Contracts: Competition and Contract Implications. William and Mary Law Review, 52(2). Available at https://scholarship.law.wm.edu/wmlr/vol52/iss2/2

Preston, C., \& McCann, E. W. (2012). Unwrapping Shrinkwraps, Clickwraps, and Browsewraps: How the Law Went Wrong from Horse Traders to the Law of the Horse. Brigham Young University Journal of Public Law, 26(1). Available at https://digitalcommons.law.byu.edu/jpl/vol26/iss1/2

Rayward, W. B. (1994). Visions of Xanadu: Paul Otlet and Hypertext. Journal of the American Society for Information Science, 45(4). doi:10.1002/(SICI)1097-4571(199405)45:4<235::AIDASI2>3.0.CO;2-Y

Draft of the Restatement of Consumer Contracts. (2019). American Law Institute.

Restatement of the Law Second, Contracts. (1981). American Law Institute.

Richter, D. H. (Ed.). (2007). Aristotle. In The Critical Tradition: Classic Texts and Contemporary Trends (3rd ed, pp. 55-58). Boston: Bedford/St. Martin's.

Romm, T. (2018, February 14). The U.S. Government and Facebook are Negotiating a Record, Multibillion-Dollar Fine for the Company's Privacy Lapses. The Washington Post. Retrieved from https://www.washingtonpost.com/technology/2019/02/14/us-government-facebookare-negotiating-record-multi-billion-dollar-fine-companys-privacylapses/?noredirect=on\&utm_term=.o3da770e7abe

Rosenberg, M., Confessore, N., \& Cadwalladr, C. (2018, March 17). How Trump Consultants Exploited the Facebook Data of Millions. The New York Times. Retrieved from https://www.nytimes.com/2018/o3/17/us/politics/cambridge-analytica-trump-campaign.html

Rowley, K. A. (2011). Contract Terms. Retrieved from https://law.unlv.edu/faculty/rowley/KTermsSp11.pdf

Korobkin, R. (2003). Bounded Rationality, Standard Form Contracts, and Unconscionability. University of Chicago Law Review, 70(4), 1203-1295. Available at https://chicagounbound.uchicago.edu/uclrev/vol7o/iss4/2/

Russell, A. (2014). Open Standards in the Digital Age. Cambridge: Cambridge University Press. Sales, H.B. (1953). Standard Form Contracts. The Modern Law Review, 16(3). Retrieved from https://www.jstor.org/stable/1091838 
Mysore Sathyendra, M., Wilson, S., Shaub, F., Zimmeck, S., \& Sadeh, N. (2017). Identifying the Provision of Choices in Privacy Policy Text. Proceedings of the 2017 Conference on Empirical Methods in Natural Language Processing, 2774-2779. doi:10.18653/v1/D17-1294

Schwartz, A., \& Wilde, L. L. (1979). Intervening in Markets on the Basis of Imperfect Information: A Legal and Economic Analysis. University of Pennsylvania Law Review, 127(3), 630-682. Available at https://scholarship.law.upenn.edu/penn_law_review/vol127/iss3/2/

Singh, J., Cobbe, J., \& Norval., C. (2018). Decision Provenance: Harnessing data flow for accountable systems Compliant \& Accountable Systems. IEEE Access, 7, 6562-6574. doi:10.1109/ACCESS.2018.2887201

Stark, T. L. (2007). Drafting Contracts: How and Why Lawyers Do What They Do. New York: Aspen Publishers in Wolters Kluwer.

Sullivan, M. (2012, January 19). Attack of the Fine Print. MarketWatch. Retrieved from http://www.smartmoney.com/spend/technology/attack-of-the-fine-print-1326481930264/

Svenonius, E. (2009). The Intellectual Foundation of Information Organization. Digital Libraries and Electronic Publishing. Cambridge, MA: The MIT Press.

Tanselle, G. T. (1975). Problems and Accomplishments in the Editing of the Novel. Studies in the Novel, 7(3), 323-360. Retrieved from https://www.jstor.org/stable/29531734

Tanselle, G. T. (1978). The Editing of Historical Documents. Studies in Bibliography, 31, 1-56. Retrieved from https://www.jstor.org/stable/40371673

United States of America Federal Trade Commission. (2011). Agreement Containing Consent Order in the Matter of Facebook, Inc., a corporation [File No. 092 3184] Retrieved from https://www.ftc.gov/sites/default/files/documents/cases/2011/11/111129facebookagree.pdf

Venturini, J., Louzada, L., Maciel, M., Zingales, N. Stylianou, K., \& Belli, L. (2016). Terms of Service and Human Rights: An Analysis of Online Platform Contracts (2nd ed.; F. Jardim \& C Hirsch, Trans.). Rio de Janeiro: Editoria Revan. Available at https://bibliotecadigital.fgv.br/dspace/handle/10438/18231

Wachter, S., Mittelstadt, B., \& Russell, C. (2017) Counterfactual Explanations Without Opening the Black Box: Automated Decisions and the GDPR. Harvard Journal of Law and Technology 31(2), 841-887. Available at https://jolt.law.harvard.edu/assets/articlePDFs/v31/Counterfactual-Explanations-without-Ope ning-the-Black-Box-Sandra-Wachter-et-al.pdf Preprint retrieved from https://arxiv.org/abs/1711.00399

Wilson, S., Schaub, F., Dara, A. A., Liu, F., Cherivirala, S., Leon, P. G., ... Sadeh, N. (2016). The Creation and Analysis of a Website Privacy Policy Corpus. Proceedings of the 54th Annual Meeting of the Association for Computational Linguistics - Long Papers, 1330-1340. Available at https://www.aclweb.org/anthology/P16-1126

Yeo, G. (2007). Concepts of Record (1): Evidence, Information, and Persistent Representations. American Archivist, 7o(2), 315-343, doi:10.17723/aarc.70.2.u327764v1036756q 


\section{FOOTNOTES}

1. I refer to the combination of these genres as standard form consumer contracts (SFCCs) throughout this paper.

2. Relying on this hypothesis has been called the "cornerstone" to a law and economics approach to standard form contracts (Bakos et al., 2014, p. 5). Based on the idea that imperfect information in a market does not need to be safeguarded against, which first appeared in Swartz and Wilde (1979), an informed minority hypothesis that claims "regulation is effective if it at least increases the proportion of informed consumers to a critical mass able to influence sellers' decisions" (D’Agostino, 2015).

3. Leib and Eigen (2017) cite a difference in two distinctive cohorts' (i.e., those under 35 and those over 35) perception of zombie contracts: for people under thirty-five years old, they are more familiar with hyperlinks in footers than the little pamphlets of papers that dictated the privacy policies previously mailed periodically with each credit card.

4. In new authoritative documents such as the American Law Institute's (ALI) recently proposed Restatement of Consumer Contracts (Klass, 2019; Levitin, 2019).

5. This is a reference to Omri Ben-Shahar's (2014) quote in "More than you wanted to know: The Failure of Mandated Disclosure" where he assumes users would rather know the features of a product such as the ability for an iPhone screen to not be scratched by keys rather than a piece of salient information in a SFCC such as the jurisdiction of the contract to which they agree.

6. (Advocates for Basic Legal Equality, Inc. et al., 2018).

7. Seen in recent authoritative documents such as the American Law Institute's (ALI) recently proposed Restatement of Consumer Contracts.

8. "I Agree" buttons versus browsewrap that relies on more ambiguous notions of action consistent with consent. While the notion that actually clicking "Agree" makes an agreement more valid seems to make sense, when it comes to consent, the type (i.e., clickwrap over browsewrap [4]) only increases reading by a tiny margin of $0.36 \%$ (Marotta-Wurgler, 2011). Mandatory disclosure methods have been well established as ineffective (Ben-Shahar and Schneider, 2014), even if the default remedy throughout much regulatory discourse (e.g., UETA’s “posting rule”, GDPR's transparency requirements).

\section{9. https://www.eff.org/issues/terms-of-abuse}

10. Studies have shown (Korobkin, 2003; Ayers and Schwartz, 2014) that salient terms can be generally limited to two to five terms, for instance, based on the limits of our psychology and/or what has been found to be considered 'unexpected'. Russell Korobkin (2003) wrote an oft-cited article that described how two to three salient points, for instance, fulfill the extent of our psychological understanding of terms on average. Ayers and Schwartz have called this process 'term optimization', and it might involve surveys, or other means to gather information about users' knowledge of the terms, their interest in certain terms as salient, and their ability to understand the terms they encounter.

\section{1. http://www.gutenberg.org/files/22910/22910-h/22910-h.htm}

12. Leff, 1967, p. 505, footnote 68 
13. To clarify, the term "individualized" here is being used to describe the customized relationships within each status relationship, not the Individual that is associated with liberation by standardisation.

14. Plato (in Gorgias) blamed misuse of persuasive language on the orator (i.e., the Sophist) whom did not believe that people could "obtain absolute knowledge" and thus "concerned themselves only with probabilities” (Richter, 2007, p. 81). Rhetoric according to Plato should be based on discourse that is "analytic, objective, and dialectical", rather than "synthetic" or "emotional" (p. 81). Instead of producing "mere appearances of truth" like the Sophists, without regard for whether or not it is transcendently true, Plato argued for a type of rhetoric that could distinguish the truth behind such appearances.

15. For example, a statement on Facebook frames one choice as: "if you keep face recognition turned off, we won't be able to use this technology if a stranger uses your photo to impersonate you" (p. 22).

\section{6. https://usableprivacy.org/learn_more}

\section{7. https://wheatoncollege.edu/academics/special-projects-initiatives/lexomics/lexos- installers/}

18.

http://docs.oasis-open.org/legalxml-econtracts/CSo1/legalxml-econtracts-specification-1.o.ht $\mathrm{ml}$

19. There is evidence that "drafting isomorphism is prevalent, and that it results in over-drafting with duplicate clauses, inconsistent terms, and clauses retaining 'ghosts' of other contracts found in form contracts.” (Leib and Eigen, 2017, p. 83)

\section{0. https://www.aiacontracts.org/contract-doc-pages/21536-what-we-do}

\section{1. https://www.verisk.com/insurance/brands/iso/about/}

22. G. Thomas Tanselle (1975) claimed that edits of a text should be recognized as two types: 1) vertical revision, or one that "aims at attempting to make a different sort of work," and 2) horizontal, which "aims at intensifying, refining, or improving the work" (p. 330). This idea from bibliography provides an articulation of the rationale behind certain changes (Tanselle, 1978), which could be one example of more meaningful documentation practices when applied to SFCCs.

23. Stiglitz (2000) identifies asymmetric information as one of the major departures from previous economic theory and the major market failure presented by the information age.

24. The UETA contains a section entitled 'Time and Place of Sending and Receipt', which states that an electronic record is deemed to be sent when it is properly addressed or directed to another recipient, is in a form capable of being read by the other parties' system and when it is out of the control of the sender [...] Additionally, 'an electronic record is deemed received when it enters an information processing system designated by the recipient for receiving such messages (e.g., home office), and it is in a form capable of being processed by that system." (Section 15 of the UETA) (Ibrahim et al., 2007). 